\title{
COMO SE CONSTRÓI UM ARTESÃO - NEGOCIACÕOES DE SIGNIFICADO E UMA "CARA NOVA" PARA AS "COISAS DA VOVÓ"
}

\author{
Aline Sapiezinskas \\ Doutora em Antropologia Social - Brasil
}

Resumo: O artigo propõe discutir como se forma o chamado "artesanato de design", localizado na confluência entre as práticas do mundo técnico do design e os "saberes e fazeres tradicionais", passados de geração em geração. Partindo da experiência de campo com artesãs de Brasília, procuro desvendar como se forma a noção de que sua produção deve atender a determinados requisitos formais e estéticos para ir ao encontro das expectativas do consumidor e ganhar o mercado. Essa discussão questiona vários "mitos" acerca do trabalho artesanal e põe em relevo as disputas simbólicas que se processam entre artesãs, designers e instituições organizadoras. Abordar o artesanato de Brasília como sendo um campo, com referência à teoria dos campos de Pierre Bourdieu, nos permite identificar os atores sociais envolvidos e os papéis desempenhados por eles. Revela, ademais, os jogos de poder que instituem práticas e conformam esse campo. Associo a abordagem de Bourdieu ao interacionismo simbólico de Georg Simmel e Erving Goffman, guardadas as particularidades de cada autor, ambas compartilhando de uma noção de realidade social construída através da vivência ou experiência dos atores no contexto vivido. Estas são as principais referências que sustentam a análise, somadas a Geertz, que destaca a importância do contexto e da interpretação na antropologia simbólica.

Palavras-chave: artesanato, burocracia, representação, saberes tradicionais.

Abstract: This article aims to discuss how it is formed the so called "design artcraft", which comes to life with the convergence of technical practices of designers and the "traditional knowledge" of artisans. This knowledge is said to be passed from generation to generation. Taking into account my fieldwork experience with artisans in Brasilia, I try and unveil how emerges the notion that artcraft production should follow formal and aesthetical requirements in order to please the consumers and thus succeed in the market. Some "myths" regarding the artcraft work are put at stake on

Horizontes Antropológicos, Porto Alegre, ano 18, n. 38, p. 133-158, jul./dez. 2012 
the paper, which shows how symbolic disputes among artisans, designers and institutions emerge in the field. I chose to approach artcrafts in Brasilia as a field, in accordance to the concept of Pierre Bourdieu. By so doing, I was able to identify the most relevant social actors and the roles they play in this specific case. This concept also allows me to reveal the power struggles that institute practices and form this field. I try to link Bourdieu's approach to the symbolic interactionism of Georg Simmel and Erving Goffman. Although these authors have their particularities, both share the common notion of a social constructed reality through the experience of the actors within a specific context. In addition to these references, I also incorporated in my analysis a perspective of Geertz, who emphasizes the importance of the context and interpretation for the symbolic anthropology.

Keywords: artcrafts, burocracy, representation, traditional knowledge.

Uma artesã não se torna uma artesã apenas porque está empregando uma técnica artesanal, mas porque está inserida num contexto em que ser uma artesã possui um significado social em articulação com outros significados, dos quais ela compartilha. Essa simples observação coloca em relevo o contexto cultural, ou dito de outra forma, a relevância da contextualização das práticas observadas. Essa é a proposta de Geertz (1989, p. 89), para quem o homem é um animal simbolizante, conceptualizante e pesquisador de significados. Para entender um objeto antropológico, assim, é preciso desvendar sua lógica simbólica, a lógica que orienta as práticas dos atores dentro de um campo específico, incluindo os conceitos com os quais estão lidando, mesmo que eles não se deem conta de que estão tratando de conceitos. Esse autor resgata a concepção weberiana do homem como um animal "amarrado a teias de significados que ele mesmo teceu" e concentra no conceito de cultura a chave para a compreensão desses significados. Ele salienta que os mesmos processos ocorrem nos diversos âmbitos da cultura que se queira tomar como análise. Uma mesma lógica reside e opera tanto na economia quanto na religião ou nas artes, sendo a definição do objeto de análise apenas um dos meios possíveis de abordar tal sistema de significados.

Principio, assim, pela caracterização do contexto social das mulheres de Brasília, expondo a problemática que a maioria delas relata vivenciar, especialmente relevante para compreender o período que antecedeu o seu ingresso nos grupos de trabalho com artesanato, os fatores que as motivaram a começar 
e o que a atividade artesanal representa para elas hoje em dia. As entrevistas foram realizadas em Brasília, na maioria, em Samambaia e Taguatinga, com dois grupos de produção artesanal conhecidos respectivamente como "Flor do Cerrado" e "Bordadeiras de Taguatinga", entre os anos de 2006 e 2007. A problemática abordada conserva a relevância, o que se observa pelo aumento de grupos de trabalho nos últimos anos, com experiências e resultados semelhantes, e pela difusão desse tipo de projeto de empreendedorismo sociocultural por todo o Brasil.

As características principais da mulher brasiliense que se beneficia de projetos de produção artesanal incluem a proveniência de camadas de mais baixa renda, a pouca instrução e a dificuldade de emprego. Essas mulheres tendem a concentrar seus afazeres no cuidado da casa e dos filhos, e vislumbram pouca alternativa a isso. A maioria das mulheres entrevistadas era proveniente do meio rural, acostumada ao trabalho da roça, e veio para Brasília acompanhada, seja dos pais, de um namorado ou marido, em busca de melhores oportunidades de vida.

As possibilidades de trabalho, quando surgem, são de empregada doméstica, auxiliar para serviços gerais, copeira ou babá. Para isso é necessário, no mínimo, ter bons contatos, para conseguir uma indicação. A falta de algum treinamento específico ou experiência anterior, que é também requerida, para muitas representa um grande obstáculo. Administrar a casa e cuidar das crianças, apresentando uma média de três filhos cada, requer tempo, disposição e muito trabalho. Muitas delas criam os filhos sem nenhuma ajuda do marido, companheiro ou pai das crianças.

Essa mulher de poucos recursos se vê numa situação praticamente sem solução para prover o sustento familiar, ingressar no mercado de trabalho e obter um meio de vida. Como vai sair e deixar os filhos pequenos sozinhos em casa? Como vai fazer para conseguir um emprego que permita pagar a creche dos filhos, onde eles poderiam ficar enquanto ela está fora, ou que outra pessoa poderia tomar conta deles em seu lugar? Esses são dilemas que essa mulher se vê forçada a enfrentar.

Muitas vezes, esse tipo de situação acaba resultando no ingresso dos filhos no trabalho muito cedo. As crianças são mandadas às ruas para vender balas, chicletes ou pequenos objetos, para lavar carros ou mesmo para pedir dinheiro no meio do trânsito, como forma de ajudar na renda familiar. Tal situação gera um círculo vicioso de reprodução da miséria e vulnerabilidade 
social, pois a criança que troca a escola pelo trabalho torna-se um adulto sem qualificação específica para o trabalho.

Essa situação, que atinge parte considerável da população brasileira, explica o sucesso de programas como o "Bolsa Família", do governo federal, iniciado no governo do presidente Luiz Inácio da Silva e ainda em vigor no governo da presidenta Dilma Rousseff, ou o "Renda Minha", programa de características semelhantes, gerido pelo governo do Distrito Federal. Tais programas oferecem um auxílio em dinheiro para que a mulher mantenha os filhos na escola e possa ficar em casa e tomar conta deles no turno que não corresponde ao horário escolar. ${ }^{1}$

A maioria das mulheres de baixa renda de Brasília, dentre as entrevistadas, relata ser beneficiária de pelo menos um dos programas de renda dos governos. Tendo o sustento básico da família garantido, ainda que de forma um tanto quanto limitada, a mulher consegue pensar em si mesma e buscar em si os recursos para ingressar no mercado de trabalho.

As mulheres dos grupos de produção de artesanato em Brasília que acompanhei, reunidas, conseguiram encontrar um modo de lidar com essa situação de vulnerabilidade social. Administrando casa e família, acompanhando os filhos pequenos, e ao mesmo tempo garantindo seu sustento ao exercer atividade remunerada, as artesãs de Brasília que analiso são exemplo de sucesso que alia determinação, vontade de trabalhar e criatividade. Ao tratar desse tema, sou levada a questionar alguns mitos do imaginário ligado ao artesanato, como, por exemplo, o de que o artesão é figura desinteressada dos resultados de seu ofício e alienado do contexto social em que vive. O convívio com as artesãs e a compreensão do funcionamento desse universo revela outras dimensões de suas existências e também das complexas relações que estão em jogo.

Hoje nós, o interior, os brasileiros, estão valorizando o artesanato brasileiro. Por quê? Porque antes eles só ficavam pensando no que eles iam trazer de fora, então hoje teve, sim, uma mudança na cultura das pessoas muito grande, não tem mais aquele raciocínio do artesão "paz e amor" que andava lá debaixo da torre... um hippie que fazia de manhã pra comer de tarde. ${ }^{2}$ (Roze Mendes, Flor do Cerrado).

\footnotetext{
1 Não cabe discutir aqui os méritos e deficiências de tais iniciativas. É inegável que tais programas têm impacto social, o que foi possível constatar no trabalho de campo.

2 A torre mencionada é a torre de televisão de Brasília, local onde costumava ter uma grande e variada feira de artesanato.
} 
Partindo da percepção de uma mudança na concepção do que representa ser uma artesã no mundo de hoje, Roze demonstra que se sente confortável diante da perspectiva de formação de um mundo globalizado, em que o artesanato ganha novos significados e transforma-se numa profissão.

A ajuda financeira recebida do governo permite dar um primeiro passo no sentido de buscar espaço no mercado de trabalho desenvolvendo atividade produtiva. O passo seguinte consiste em identificar os canais institucionais por meio dos quais a dona de casa pode tornar-se artesã. Ali atuam ONGs, associações de vizinhança, a Secretaria do Trabalho do Governo do Distrito Federal e o Sebrae. Não se trata de um caminho único, mas de inúmeras possibilidades. Vou me concentrar na atuação do Sebrae, órgão de parceria público-privada que oferece informação e treinamento para as artesãs, com foco no mercado consumidor.

Ao buscar a ajuda do Sebrae para encontrar os caminhos do trabalho produtivo, a mulher é orientada a investir naquilo que ela já sabe. Nesse momento, entram em jogo as habilidades "naturais" de cada uma.

O Sebrae orienta a mulher a focar-se naquilo que ela faz de melhor. O termo "natural" aparece aqui como se, na natureza da mulher, houvesse uma predisposição para trabalhos manuais com agulhas, como bordados ou costura, e para a produção de objetos com fins decorativos. Sabemos que tais características, bem como sua quase total exclusividade no cuidado dos filhos, são parte da construção cultural do papel social feminino. Aqui já nos deparamos com um primeiro mito: da familiaridade da mulher com as agulhas. Retomo mais adiante essa questão.

O Sebrae vê no universo do trabalho informal uma grande área de atuação para seus projetos de desenvolvimento e o "apoio" oferecido surge como uma forma de inserir esse público aparentemente disperso numa rede estruturada de relações, enquadrando de alguma forma esse setor informal numa das categorias previamente estabelecidas pela instituição. Ao "apoiar", "ajudar" e "proteger" ao mesmo tempo, o Sebrae exerce seu poder sobre o universo informal, estabelecendo o idioma em que ocorrem as conversas e definindo ele próprio os termos da ajuda.

Segundo Erving Goffman (1986), a sociedade estabelece as categorias a partir das quais classifica os indivíduos e também define o conjunto de atributos que os indivíduos têm de preencher para fazer parte delas. As interações sociais seriam baseadas em tais categorias e no conjunto das expectativas dos 
atores sociais sobre os atributos dos indivíduos que se encaixam nelas. As categorias empregadas pelo Sebrae para definição dos beneficiários de suas políticas são bem claras, conforme se pode observar no website da instituição. O propósito é apoiar o empreendedorismo e a criação de micro e pequenas empresas. Então ficamos nos perguntando como é que uma instituição com essa finalidade está promovendo políticas públicas de incentivo ao artesanato e atuando visivelmente no setor informal? E ainda, como esses procedimentos se encaixam no quadro geral das suas atividades?

Aplicando a visão de Goffman (1967) às estruturas que fundamentam a prática burocrática, restaria ainda a ser observado o outro lado da moeda, que diz respeito aos usos maleáveis dessas categorias executados pelos indivíduos que estão lidando com elas no dia a dia, ou seja, o ponto de vista da pragmática, interessada nos significados simbólicos das categorias construídas tal como são atualizadas pelos atores no uso cotidiano.

Essa dimensão se revela na fala dos próprios atores sobre como são empregadas as categorias definidas pela instituição. Quando Antonieta Contini, gerente do Sebrae para projetos de desenvolvimento local, explica sua metodologia de trabalho e seus objetivos, ela emprega os termos dados pelo Sebrae, ao mesmo tempo em que explica como eles são entendidos, revelando os significados simbólicos dentro daquele contexto específico em que são aplicadas categorias mais amplas.

Ela explica que a metodologia parte da "identificação das potencialidades" do grupo, mas "muitas vezes elas não sabem fazer nada", ou seja, não trazem para o Sebrae aquelas práticas artesanais tradicionais, que são descritas como o ponto de partida de todo o trabalho de "resgate" que seria feito em seguida. Nesse caso, a "identificação das potencialidades" é entendida como uma negociação com o grupo de mulheres sobre o tipo de trabalho que elas estariam dispostas a "aprender" a fazer, o que se verifica ao serem em seguida encaminhadas para a etapa de "capacitação".

Cada um dos termos da metodologia descrita por Antonieta Contini se presta a um leque de interpretações possíveis, na análise dos significados simbólicos dos termos desse discurso, empregado no intuito de adequar o programa às circunstâncias encontradas em campo, servindo a diversas aplicações práticas possíveis dessas interpretações.

Michael Herzfeld (1992) propõe análise dos significados simbólicos dos usos de categorias de classificação na prática burocrática da administração de 
uma cidade na Grécia. Esse autor salienta a importância de se observar os usos da retórica para além das categorias de classificação, como condição mesma da possibilidade de negociação entre as formas fixadas em palavras e o seu uso aplicado aos casos concretos: "Rhetoric is not simply the pure art of classification. It is the practice of symbolic action - a process in which fixed form is often not only the mask, but even the enabling condition, for labile meaning." (Herzfeld, 1992, p. 69).

Ele define essa manipulação por meio da retórica das categorias de classificação que se apresentam fixadas em palavras como a prática da ação simbólica mesma, que garante a possibilidade das manobras no campo simbólico.

Podemos extrapolar o pensamento de Herzfeld e afirmar que a prática dos atores na manipulação das categorias e formas de classificação da burocracia por meio da manipulação dos significados e da prática da retórica promove a reatualização das categorias em si, uma vez que elas são reificadas pela referência que se faz a elas, sendo continuamente vivificadas e atualizadas, permitindo novas interpretações que venham se juntar a essas no futuro.

Segundo informação institucional do Sebrae:

O Sebrae, Serviço Brasileiro de Apoio às Micro e Pequenas Empresas, trabalha desde 1972 pelo desenvolvimento sustentável das empresas de pequeno porte. [...] Para isso promove cursos de capacitação, facilita o acesso a serviços financeiros, estimula a cooperação entre as empresas, organiza feiras e rodadas de negócios e incentiva o desenvolvimento de atividades que contribuem para a geração de emprego e renda. [...] São centenas de projetos gerenciados pelas Unidades de Negócios e de Gestão [...]. (Sebrae Nacional, 2009).

A relação entre conhecimento, reconhecimento e poder, apontada por Pierre Bourdieu (2000, p. 11), nos oferece uma chave para a análise da relação do Sebrae com os beneficiários dos seus programas de treinamento:

As relações de comunicação são relações de poder que dependem, na forma e no conteúdo, do poder material ou simbólico acumulado pelos agentes (ou pelas instituições) envolvidos nessas relações e que, como o dom ou o potlatch, podem permitir acumular poder simbólico.

De acordo com Bourdieu, as diferentes classes estão envolvidas numa luta simbólica pela imposição de uma definição específica do mundo social que esteja mais de acordo com os seus interesses. Tal luta poderia ser travada 
diretamente ou por meio dos especialistas da produção simbólica, que teriam o poder de impor instrumentos de conhecimento e de expressão arbitrários. Nesse caso específico, os cursos e treinamentos do Sebrae concorrem para adequar o trabalho das mulheres ao modelo próprio dessa instituição, adequando as artesãs ao formato de grupos de trabalho, e os grupos de trabalho ao formato de associações, incentivando o empreendedorismo para que essas, talvez, transformem-se em microempresas, e assim por diante. Na atuação dos consultores, especialistas no manejo de recursos simbólicos, pode ser percebida uma ação no sentido de transformação do objeto artesanal que acompanharia a própria transformação da visão de mundo que ocorre com a inserção das artesãs no universo do mercado consumidor.

O poder simbólico como poder de constituir o dado pela enunciação, de fazer ver e fazer crer, de confirmar ou de transformar a visão de mundo, e deste modo, a acção sobre o mundo, portanto o mundo; poder quase mágico que permite obter o equivalente daquilo que é obtido pela força, graças ao efeito específico da mobilização, só se exerce se for reconhecido, quer dizer, ignorado como arbitrário. (Bourdieu, 2000, p. 14).

O "poder de constituir o dado pela enunciação", o poder simbólico, pode ser entendido como resultante da educação e da capacitação, que promove uma forma de expressão do indivíduo no mundo, criando ao mesmo tempo forma e conteúdo, ou seja, capacitando-o para atuar dentro de um modelo previsto de atuação. E, conforme ele explica, esse efeito ocorre graças ao caráter mobilizador dos cursos e treinamentos, e do reconhecimento daquele poder por parte dos beneficiários.

Bourdieu (2000) se concentra nos instrumentos de imposição do poder simbólico, e especialmente no processo de construção das crenças, na educação, reprodução e inculcação da capacidade de se colocar no mundo, por meio da adoção de visões de mundo marcadas por posições privilegiadas dentro do campo de poder. Entretanto, escapam ao modelo proposto por ele aqueles casos em que o indivíduo seleciona alguns aspectos da sua adesão à visão de mundo dominante, de acordo com o seu interesse pessoal, e a própria manipulação individual do conhecimento quando ele procura empregar esse capital em proveito próprio. Essa dimensão da negociação do sentido no campo das disputas se mostra sempre presente e reveladora sobre a ação individual visando o beneficio próprio. Ao longo do artigo, procuro mostrar como se dá essa negociação. 
Sobre a atuação do Sebrae, temos que

o Sistema SEBRAE busca criar, por vários mecanismos (capacitação, mobilização, disseminação do empreendedorismo e do associativismo, entre outros), um ambiente radicalmente favorável à sustentabilidade e ampliação dos pequenos negócios. Esse ambiente passa por menor carga tributária, menos burocracia, acesso ao crédito, à tecnologia e ao conhecimento. A instituição opera justamente para atenuar esses cinco grandes gargalos [...]. (Sebrae Nacional, 2009).

Nesse sentido, o Sebrae instituiu áreas prioritárias de ação que visam atender aos fatores por eles identificados como obstáculos à criação de micro e pequenas empresas, e voltou-se a apoiar o setor informal, numa tentativa de promover a inserção. Assim se explica e torna possível compreender a expansão da atividade do Sebrae, que vai até a capacitação de setores informais para, a partir dali, por meio da adoção do idioma comum e de suas práticas, aproximar aquele universo dos modelos formais de micro e pequena empresa.

A figura central nessa mediação entre a instituição formal e as artesãs acostumadas a informalidade é o designer. Ele é a pessoa que vai visitar os grupos, participar de suas atividades, conhecer e reconhecer seu potencial para poder propor um treinamento das capacidades inatas que forem identificadas. Na relação direta entre o designer e a artesã ocorre a transformação das "coisas da vovó", os saberes e fazeres tradicionais, em algo novo.

O consultor de design estabelece relações e aproxima diversas instâncias envolvidas no trabalho artesanal: 1) o Sebrae, como proponente da iniciativa e organizador de atividades, seja para formação de grupos de trabalho, seja para capacitação ou treinamento; 2) as mulheres, as produtoras em si do objeto final de consumo, vinculadas ou não ao Sebrae; e 3) o mercado consumidor de moda e design, entidade abstrata, no qual o designer seria um especialista e do qual consequentemente torna-se um representante, já que se mostra capaz de atuar e falar em seu nome.

O consultor figura como intermediário entre as práticas tradicionais de produção local e o mercado consumidor, cujas exigências estabelecem parâmetros supostamente globais de qualidade, e como promotor da identidade local, já que muitas vezes representa os objetivos do órgão propositor junto aos grupos, na comunidade. O seu papel é central, uma vez que o designer dialoga com todos os atores envolvidos, e ele próprio transita em cada uma das instâncias do processo, como se o fizesse entre diferentes mundos. O designer 
desempenha um papel importante na relação da produção artesanal com o cenário do mundo da moda. Além de definir o formato final do produto artesanal e o tipo de acabamento do produto, enfim, de transformá-lo de acordo com as expectativas dessa entidade abstrata chamada "mercado", ele também responde pela inserção desse produto no universo da moda, onde poderá receber grande destaque. Ele é o "especialista" em criação, em critérios de gosto, estilo de vida, adequação aos desejos do consumidor, cuja vontade interpreta e representa.

Antes de prolongar a análise do papel do designer, procuro elaborar uma breve revisão do tratamento de algumas dessas questões na antropologia por autores clássicos, de forma a relacionar alguns conceitos com as práticas observadas em campo, estabelecendo relações entre observação e teorização.

Georg Simmel (1971), numa série de ensaios publicados postumamente como On individuality and social forms,${ }^{3}$ lançou no começo do século passado os fundamentos teóricos de uma discussão sobre a moda, o desejo pelo objeto e a construção social do valor que ainda ecoa e provoca grande reflexão. Numa teoria que ficou conhecida como "imitação em cascata" (trickle down), o autor chama a atenção para a dialética entre diferenciação e imitação - que ocorre entre grupos na sociedade no que se refere à moda - como constitutiva da própria natureza do caráter transitório da moda. A moda seria sempre uma criação da elite, daqueles que estariam ocupando a posição mais elevada da pirâmide social, e seguiria um movimento descendente na escala social, que se daria pela imitação dos que se encontram acima por aqueles que estão abaixo. Conforme Simmel (1971, p. 302) esclarece: "The very character of fashion demands that it should be exercised at one time only by a portion of the given group, the great majority being merely on the road to adopting it." Ou, em outras palavras, "as fashion spreads, it gradually goes to its doom".

Para além do aspecto de apropriação de elementos ou traços culturais entre camadas distintas da sociedade, independentemente do fato de estarem subindo ou descendo, o aspecto que considero importante destacar na teoria de Simmel, que justifica a pertinência e atualidade da sua teoria, repousa no

3 A obra On individuality and social forms, editada e publicada em 1971 por Donald Levine, reúne ensaios e conferências que Simmel proferiu nas primeiras décadas do século passado. 
caráter efêmero do fenômeno, caracterizado como de rápida transição e constante busca por algo novo.

Ao afirmar que "quando uma moda se espalha ela gradualmente caminha para seu fim", Simmel (1971) estabelece uma relação entre desejo, imitação e morte que denota a transitoriedade das tendências da moda. Na observação do trabalho de campo se revelam as estratégias que os atores utilizam para lidar com o caráter de transitoriedade da moda, visando a continuidade das suas práticas em meio ao imperativo da mudança e renovação.

Simmel enfatiza o caráter de transitoriedade do mundo da moda, que se aplica a forma como a experimentamos hoje. $\mathrm{O}$ autor pode ser criticado por tratar da moda a partir de uma visão de sociedade que pressupõe a existência de classes sociais claramente demarcadas, o que dificultaria a aplicação da teoria ao mundo de hoje, ou poderia reduzir o interesse por sua teoria. Entretanto, podemos argumentar em seu favor que, cada vez que uma nova moda é lançada, são criados produtos para atender a cada segmento do mercado, como se fosse uma grande celebração da novidade que estaria acessível a todos os bolsos. A moda mais sofisticada de hoje já nasce acompanhada de suas variantes mais acessíveis economicamente, ao menos no caso da moda de artesanato.

As pessoas quando pensam no artesanato, elas pensam em algo sempre muito folclórico, ainda pensam muito no artesanato nordestino, numa visão muito folclórica, e o artesanato não precisa ser, ele pode ser sofisticado, trabalhado, mas não precisa ser rebuscado, uma coisa tanto que a primeira coleção que eu fiz ela teve somente preto e branco, e hoje as pessoas já fazem muito, né, mas fazem um artesanato muito alegórico, então a gente resolveu dar uma cara pra ele sofisticada, né? Essa que é a palavra: sofisticação! (Kátia Ferreira, designer do Sebrae/Apoena).

Kátia Ferreira é uma designer do Sebrae que, a partir da experiência com os grupos de produção artesanal de Brasília, desenvolveu sua própria grife, chamada Apoena. A designer deixa muito claro o projeto da organização que ela administra, inclusive no que se refere ao planejamento das coleções e na forma como ela encara o artesanato e procura transformar a imagem dessa atividade, inserindo-a no campo da moda. Adotando a "sofisticação" como palavra-chave do seu trabalho, ela não deixa dúvidas sobre como encaminha o processo de mudança da imagem do artesanato, ao adaptá-lo ao gosto do 
mercado de luxo. Para ela, o recurso a cores sóbrias como o preto e o branco seria um traço marcante dessa adaptação do artesanato, associando-o ao luxo. Por outro lado, ela identifica o artesanato "alegórico" ou "folclórico" com a visão ultrapassada do artesanato, de que sua grife tentar se diferenciar. A imagem da cliente que é o alvo do seu produto é descrita nos seguintes termos:

Fazer peças mais arrojadas pra uma mulher moderna, uma mulher que usa uma roupa de luxo e que gostaria de ter uma saia bordada, mas também não quer sair por aí parecendo que está fantasiada. Então a gente achou esse limite, sabe, esse limite aí nós encontramos dentro do artesanato um caminho pra essa roupa. Isso eu acho que foi uma coisa que deu certo na Apoena, que faz esse sucesso todo. Ele é artesanato, mas ele é clássico, a pessoa pode usar ele tranquilamente, tanto é que nós conseguimos colocar ele em lojas, né, que realmente atendem esse público. (Kátia Ferreira, designer do Sebrae/Apoena).

Quando ela afirma "ele é artesanato, mas ele é clássico" está revelando duas categorias que se encontram em oposição, sendo o artesanato ligado ao já mencionado "alegórico" ou "folclórico", enquanto o clássico seria o correspondente ao gosto do consumidor do mercado de luxo.

Entretanto, ao salientar que o produto da Apoena é pensado para um mercado de luxo, que percebe no bordado feito a mão um efeito de sofisticação e consequentemente de distinção, devido à raridade e dificuldade de tal elaboração, notamos que no caso específico dos bordados feitos em Brasília, a teoria da "imitação em cascata" (trickle down), de Simmel (1971), encontra poder explicativo, capaz de iluminar e produzir novos insights, por mostrar-se renovada, válida e atual. Não somente o bordado "tradicional" recebe um tratamento diferenciado que o colocaria numa posição elevada da escala social, no movimento ascendente, como, a partir do momento em que ele se destaca, inicia-se também o processo de imitação e o respectivo movimento descendente daquele objeto na referida escala. Disso decorre que a característica principal é a efemeridade e a rapidez do processo de "imitação em cascata", e não tanto o sentido do movimento, pois esse corre em mão dupla, quase simultaneamente.

$\mathrm{O}$ que considero fundamental são as representações que consultores como Kátia Ferreira possuem do mundo da moda. Imagens da atividade artesanal, do produto resultante, do consumidor de luxo e do seu respectivo mercado, ao qual procuram responder. Essas representações entram em jogo na sua tarefa de fazer com que o produto artesanal encontre seu mercado. São

Horizontes Antropológicos, Porto Alegre, ano 18, n. 38, p. 133-158, jul./dez. 2012 
essas representações que alimentam o sobe e desce do processo de "imitação em cascata", e se reinventam sem cessar. Como nos lembra Paul Rabinow (2002), "as representações são fatos sociais", e por isso cada uma delas conta.

São conjuntos de imagens, cosmologias ou representações do mundo da moda que orientam as práticas dos consultores de design e acabam colocando as artesãs de Brasília em contato indireto, mediado pelo objeto, com esse universo. Tais representações constituem um repertório do qual o designer lança mão e com o qual vai conformar o objeto artesanal de forma a assegurar o trânsito desse objeto nas feiras nacionais e internacionais.

O significado do objeto é o significado que lhe é atribuído pelos atores sociais num contexto cultural específico, uma vez que o objeto não possui significado prévio ou arbitrário a não ser aquele, bastante genérico, dado pela língua. O significado social do objeto é forjado nas diferentes instâncias do percurso que vai da produção à recepção, variando de acordo com o contexto cultural e a posição dos atores em questão, que são os responsáveis pela construção ou atribuição do significado.

Entretanto, a criação do objeto, uma vez que visa a uma certa inserção bastante específica, não é livre criação. Ela é conformada por regras depreendidas dessas imagens ou representações. De forma análoga, a escrita de um texto, que se conforma a regras próprias, do campo da gramática da língua e da produção textual, pauta-se também pelas representações do autor sobre quem ele é, sobre quem é o seu leitor e sobre o tipo de imagem ou mensagem que pretende construir e veicular com seu texto.

O processo de adequação do produto ao gosto do consumidor resulta num paradoxo ou numa relação dialógica. De um lado, temos um projeto de resgate da identidade das artesãs com base na proposta de construção de uma identidade local para o trabalho artesanal. Esse projeto está voltado para a inserção social da artesã e parte das mulheres no seu contexto sociocultural atual, ainda que em construção, e visa a sua continuidade e a sustentabilidade dos fazeres. De outro, temos a atuação dos designers buscando uma adaptação do trabalho artesanal, por meio da sua consultoria especializada, às exigências e preferências do mercado consumidor. Entre essas exigências está a necessidade de renovação contínua que caracteriza o mundo da moda. Ao buscar a adequação do produto a um mercado de matriz internacional, colocando a artesã em diálogo com o global, entendido como o "outro", o designer faz com que as artesãs tenham de sair do seu contexto sociocultural local. 
Depois de identificadas as habilidades "naturais" de cada uma das mulheres, passa-se a um segundo momento, quando elas são encaminhadas para cursos de capacitação naquelas habilidades específicas, apenas para "reforçar" o que já seria "natural" para elas. O Sebrae, por meio da atuação de seus consultores, se faz presente no processo de "resg ate" das habilidades "naturais" das mulheres artesãs. Por mais paradoxal que seja, Antonieta Contini, gerente de desenvolvimento local do Sebrae/DF, explica o motivo de se encaminharem as artesãs para os cursos de capacitação, já que elas se apresentam no Sebrae possuindo suas habilidades "naturais":

Não, no caso elas são artesãs, mas com trabalhos manuais, o artesão é aquele que vai na natureza, traz a madeira e transforma em uma arte, vai na natureza pega o barro e transforma em uma arte. Ele se inspira na natureza, então artesão é aquele sozinho que às vezes trabalha com a família, mas ele tem muito a cultura, muito agregada a cultura dele. Se ele é nordestino, ele não muda aquilo e continua fazendo aquilo e tem que ser assim, tem que abranger a cultura, e ele não quer muita interferência. Ele não quer interferência, a maioria. Alguns são mais abertos ao designer ... "não, eu sempre fiz assim, eu prefiro assim". Agora nós temos artesãos aqui muito atualizados, que buscam o diferencial no designer e que vendem muito mais, porque hoje o mercado é muito exigente. Não dá para ti fazer o tradicional, o tradicional tem que fazer, mas também tem que se adequar ao que está se usando na ambientação e tal. Então eu não trabalho com artesã, eu trabalho muito mais com grupo de mulheres e a diferença é que é trabalhos manuais, resgatando técnicas artesanais brasileiras.

Antonieta explica como é visto e entendido o trabalho do artesão naquela instituição, ponderando sobre uma maior ou menor abertura do artesão para a interferência do designer no seu trabalho. Na sua avaliação, os artesãos que são "muito atualizados", "buscam o diferencial no designer" e "vendem muito mais". Seguindo a mudança na concepção do papel do artesão de hoje, conforme apontada por Roze, da Flor do Cerrado, o artesão "atualizado" estaria interessado na possibilidade de "vender mais". Para tanto, Antonieta Contini explica que "não dá pra ti fazer o tradicional, o tradicional tem que fazer, mas também tem que se adequar ao que está se usando", ou seja, seria preciso unir $\mathrm{o}$ artesanato tradicional às tendências da moda. Antonieta menciona também $o$ "resgate" de técnicas artesanais brasileiras, retomando o que teria sido o ponto de partida do trabalho artesanal: aqueles conhecimentos tradicionais que as 
mulheres já possuíam naturalmente e que seriam "aperfeiçoados" por meio dos cursos de capacitação do Sebrae.

Nessa etapa entra em jogo a ideia de "coisas que a vovó fazia", que consistiria em conhecimentos que não foram aprendidos formalmente, mas transferidos de mulher para mulher no jogo de reprodução de papéis sociais. Seriam conhecimentos tradicionais herdados e compartilhados por alguns membros da sociedade que, em geral, dependem de alguma habilidade manual específica. Antes de receberem o designer, que vai "desenvolver" um produto para as artesãs, elas precisam fazer um curso para "lembrar dos pontos de bordado que aprenderam com as avós", conforme foi mencionado tanto pelas artesãs, como por Antonieta Contini e pelos designers. Antes de começarem a produzir o artigo "de design", seria preciso fazer o "resgate" daquilo que as mulheres já sabem fazer, o que seria feito por meio de um curso de capacitação em bordado ou costura.

O fato de que tal "resgate" seja feito por meio dos cursos de capacitação não parece suscitar nenhum estranhamento entre os nativos desse universo do artesanato de Brasília, que se referem aos cursos como uma forma de aprimoramento dos saberes "naturais" das mulheres. A única ponderação que tem sido feita se refere ao fato de que algumas mulheres não "levam jeito" para fazer trabalhos manuais. Portanto, se o trabalho manual ou com agulhas fosse algo tão natural para as mulheres, como se explica que algumas simplesmente "não levam jeito"?

Gerente, designers e artesãs empreendedoras explicam que "é preciso saber se uma pessoa tem jeito pra isso" antes de lhe transmitir o conhecimento. Muitas mulheres tentar aprender o bordado ou a costura, mas não "levam jeito pra isso". Aquelas que não "levam jeito" acabam sendo orientadas a continuar na busca pela sua principal habilidade, entendida como um "dom". A justificativa para esse processo de "resgate" encontra-se na crença de que cada membro da sociedade possui "dom" para alguma coisa, uma habilidade e predisposição natural, recebida gratuitamente como presente, para a realização de algum tipo específico de tarefa. Descoberto o dom, ele precisa ser aceito e utilizado para o bem de todos, como forma de retribuição.

A existência dos "dons" ligados aos "fazeres tradicionais" nesse contexto de globalização e modernidade tardia acaba por transformar o próprio significado do "dom", que se transforma em algo além de uma habilidade inata, para ser também a forma como uma pessoa vai se inserir no sistema econômico, 
seja no mercado de trabalho, como produtor, seja diretamente no mercado consumidor.

No Ensaio sobre a dádiva, Marcel Mauss (2001) trata do dom como recurso empenhado num sistema de trocas, que representa tanto um investimento econômico para ser resgatado no futuro quanto investimento na construção da honra e do prestígio no momento presente para aquele que se desfaz do bem. Traçando um paralelo com as artesãs, o "resgate" dos "dons" tanto representaria uma possibilidade de ganho de prestígio por meio da descoberta de uma nova oportunidade de trabalho e possível geração de renda, já no presente, quanto um possível investimento também no futuro, através dos desdobramentos dessa atividade, caso a sua inserção no mercado frutifique.

Com isso, somos forçados a nos apartar daquela ideia romântica do artesão que vive meio isolado do mundo, produzindo um artefato apenas pela "arte", ou simplesmente para ser vendido a preços baixíssimos no meio da calçada de uma rua qualquer. $\mathrm{O}$ artesão de que estamos tratando está inserido numa rede de relações, vive num mundo globalizado, em que exportação e feiras internacionais não são realidades tão distantes. O mesmo tipo de observação sobre a mudança no significado do artesanato e do papel do artesão na sociedade de hoje foi mencionado tanto por Roze Mendes, da Flor do Cerrado, como por Kátia Ferreira, da Apoena, quase nos mesmos termos. A busca por conquistar o mercado consumidor torna-se uma etapa necessária para garantir a sustentabilidade do projeto de artesanato com finalidade de geração de renda, e não um fim em si mesmo. Observar esse dado permite a apreensão de novos significados para as antigas práticas.

Além da importância do domínio do manejo das técnicas artesanais, "resgatadas" pelo Sebrae na sua atuação junto aos grupos de trabalho, entra em jogo também o tipo de material empregado nas confecções. O tipo de material aparece como parte da caracterização da atividade artesanal, como constitutivo da própria definição de artesanato.

Isso se expressa no processo de "atualização ou modernização" da atividade artesanal, quando se dá a busca pelos materiais mais naturais, mais ecologicamente corretos. Esses são preferidos não apenas por serem bons em si mesmos, porque ser ecologicamente viável já representaria um valor em si, mas também porque o produto ecologicamente correto atenderia também a um segmento de mercado definido, e tal característica agregaria valor ao produto. 
Não somente a sustentabilidade ambiental atrairia o consumidor e agregaria valor ao produto. Segundo Renato Imbroisi, consultor de design do Sebrae: "Para saber se o produto vai agradar o consumidor, a pesquisa de mercado, e o que conta a história do produto faz essa diferença. Além do produto em si, a história que tem por trás." A pesquisa de mercado ajuda a revelar os desejos do consumidor, em compasso com as tendências da moda. Mas o designer revela ainda que parte da estratégia de promoção do produto artesanal repousa nas histórias ou narrativas que acompanham esse produto, revelando detalhes tanto sobre as pessoas que o produzem, o tipo de comunidade em que é feito, quanto no que tange ao impacto social dessa comercialização, bem como as etapas do processo de produção, que de um modo geral empregam materiais reciclados e recursos naturais.

As Bordadeiras de Taguatinga utilizam somente tecidos de algodão natural, que deve ser pré-lavado antes de se iniciar o bordado, para que não encolha quando for lavado pela segunda vez, necessária após o término da aplicação dos fios de linha do bordado. A Flor do Cerrado, por sua vez, utiliza as folhas secas dos arbustos do cerrado, que são colhidos no campo, mas atua com "consciência ecológica" para não danificar o ecossistema do cerrado, retirando um pouco por vez, de forma a garantir a sustentabilidade dos recursos naturais. Conforme o relato de Roze Mendes, cada vez que vai ao cerrado em busca de matéria-prima, ela aproveita para juntar e trazer para casa uma enorme quantidade de lixo que as pessoas deixam jogado nos campos, e que prejudica o meio ambiente. Parte da sua tarefa consiste na luta pela preservação desse ecossistema. Analisando dois modos distintos de trabalhar com o artesanato, podemos perceber que todos eles compartilham dessa característica de vinculação da atividade artesanal com a preservação do meio ambiente.

O cuidado com a natureza e a consciência da necessidade de preservação, bem como da importância da reciclagem para o meio ambiente, constituem uma tendência da moda que está conectada com o discurso ecológico internacionalmente difundido. Ao mesmo tempo, estar sintonizado com tal discurso representa em si um capital simbólico, nos termos de Bourdieu (cf. 1999, 2000, 2002), e resulta numa "estória" sobre o valor desse produto, que é vendida conjuntamente com ele. O produto artesanal não é apenas um objeto, mas um kit que inclui objeto e discurso, recorrendo ao contexto da produção para retirar dali as referências culturais deslocadas que concorrem para forjar o significado conforme ele parece ser mais apreciado. Se aqui a razão prática 
se faz presente, nos termos de Marshall Sahlins (1976), visando o comércio de "bits de cultura" por meio desses discursos, inegavelmente ela se faz acompanhar de representações, que são fatos sociais relevantes, compartilhadas por esse público consumidor, permitindo a revelação dessa camada de sentido.

Se existe a possibilidade do designer responder aos apelos do mercado fornecendo um produto com um discurso, um kit, isso ocorre antes porque existem essas representações entre as consumidoras, que esperam manifestar sua consciência ecológica e social através da aquisição dos produtos, do que pela simples razão prática de que os kits vendem bem.

Dessa forma, a aquisição de produtos artesanais é vista como um ato de cidadania e expressão de consciência social, como forma de mostrar um consumo crítico ou de se posicionar contra o "consumo conspícuo" de que fala Veblen (1974). O fato de que tais kits artesanais, objeto e discurso, são produzidos de acordo com a orientação de um designer, revela mais do que o fato de que eles são construídos numa interação que tem foco no mercado, revela representações próprias de um outro grupo social que é constituído pelos consumidores desse tipo de produto, de que o designer seria, ao mesmo tempo, representante e intérprete.

Interessa aqui não tanto revelar a existência de uma razão prática que reduz o processo de produção artesanal ao comércio, mas a existência de diferentes representações ou cosmologias concorrendo em torno de um objeto material, numa espécie de disputa pelo significado.

Um outro aspecto importante no que diz respeito à disputa pelo significado é a batalha de classificação que ocorre quando a artesã busca o reconhecimento de sua situação profissional pelo Estado, ao inscrever-se oficialmente como artesã. O ingresso no campo formal do artesanato demanda a obtenção de um registro de artesão, que se dá com a obtenção da "carteirinha de artesão", elaborada pela Gerência de Artesanato da Secretaria do Trabalho do Governo do Distrito Federal. Em outro trabalho (Sapiezinskas, 2008), analiso os meandros do processo de registro do artesão na Secretaria do Trabalho. Aqui gostaria apenas de salientar que um dos primeiros passos no ingresso do artesão nesse campo passa pela etapa burocrática de registro. Como toda burocracia, trata-se de formas de classificação e ordenamento da atividade, e também da definição da atividade artesanal do ponto de vista do Estado.

O tipo de material como constitutivo da atividade artesanal se expressa, assim, de duas formas. A primeira, tratada até aqui, leva em conta o ponto de 
vista do designer, que busca adequar o produto ao que é desejado pelo consumidor do artesanato, indo ao encontro de sua consciência ecológica. A segunda, de que tratarei em seguida, leva em conta o ponto de vista da autoridade que representa o Estado na definição de quem é e quem não é artesão, e que passa também pela definição do tipo de material considerado apropriado para a atividade artesanal. Conforme me explicou Ana Maria França, funcionária da Secretaria do Trabalho do Governo do Distrito Federal:

A técnica que você utiliza é importantíssima, pois na medida que você utiliza, sabe pegar uma técnica e utilizar com a matéria-prima adequada para poder ter um produto aceitável no mercado de trabalho, isso para mim é artesanato. Que quando você pega uma matéria-prima que não é tão aceitada naquela técnica e você consegue fazer, obter um produto totalmente diferente, você está inovando. A criatividade ali, a originalidade está ali, então, quer dizer, para mim teria que definir, eles começam já discutindo a matéria-prima, se você faz. [...] A Secretaria do Trabalho só cadastra bijuteria natural. Mas o que a gente vê com o mercado de trabalho é que são aqueles negócios coloridos, bem rosinha, miçanga, aquelas resinas, aqueles negócios, essa não é uma matéria-prima aceitável? A Ana Maria acha que é. Mas quando eu vou fazer um cadastramento eu coloco, se você for chamado para uma exposição da secretaria o seu produto tem que ser o mais natural possível, para não fugir do artesanato, porque é uma luta que se tem, é que não se fuja. Então, eu acho importantíssimo, quando for definir o artesanato, que veja essa parte da matéria-prima. Então, se você tem uma matéria-prima " $x$ ", aplica uma técnica nela e faz um produto, com acabamento, com criatividade, aí outros conceitos, eu posso considerar isso como artesanato atualmente. Não só o indígena, o indígena é bem natural, você não vai ter que fazer a vida inteira trabalho com cabaça. Não é não? Não é?

Procurei aqui mostrar as disputas ou negociações de significados presentes nos fazeres cotidianos, vendo o consumo, por exemplo, como ativo e não como passivo, num universo de representações. Da mesma forma, entendo que a classificação burocrática vai se revelando negociada a cada momento, por meio dos procedimentos e estratégias que os atores empregam no cotidiano para a manutenção daqueles significados que lhes são mais interessantes. Procuro chamar a atenção para esses processos em que comumente não se percebe o poder de agência do sujeito, como se o consumidor ou o burocrata, por exemplo, não tivessem nenhum papel ativo a desempenhar, e seus atos fossem destituídos de significado motivado. 
$\mathrm{Na}$ fala de Ana Maria se observa que ela está lidando com conceitos, com as representações do que é um artesão e do que compõe a atividade artesanal, e do seu ponto de vista se vê capaz de questionar o próprio modo de classificação que é correntemente aplicado pela instituição. Conforme sublinhou Geertz (1989, p. 89), "as pessoas usam conceitos da experiência próxima espontaneamente, $[. .$.$] não reconhecem, a não ser de forma passageira e ocasional, que o$ que disseram envolve "conceitos'". Nessa passagem se pode observar os conceitos que estão envolvidos nas definições de artesão e da atividade artesanal, e, ainda assim, eles se veem tão presos e emaranhados nas representações do que seja um artesão e do que envolve essa atividade, de forma indissolúvel. O individuo, mesmo se dando conta dos conceitos e das limitações que eles impõem, não se vê capaz de modificar os procedimentos técnicos adotados pela instituição, que se vê maior do que os indivíduos que a compõem.

Ao mesmo tempo, nessa pequena manipulação do significado corrente, em uso, podemos constatar que a imposição de um conhecimento é um exercício de poder, do poder de quem possui o conhecimento sujeitando aquele que não o possui.

Procurei mostrar a apropriação que é feita dos conteúdos culturais transmitidos pelo treinamento e formação, ao observar como isso é utilizado pelos indivíduos em proveito próprio, ou seja, nas manobras de sentido efetuadas a partir daquilo que é apreendido, no uso cotidiano, por meio de uma negociação que visa a imposição de um significado. Procuro analisar a forma como esses recursos são empregados do ponto de vista da ação individual do sujeito, no campo dinâmico e vivo do significado corrente, também chamado de cosmologias ou representações, que subjazem às práticas cotidianas.

Conforme exposto por Eunice Durham (2004), as representações apresentam-se como "noções essencialmente sintéticas", e são apreendidas por meio do discurso. Podem também ser denominadas de "mitos", uma vez que se trata de "narrativas sintéticas que possuem significado, valor e eficácia para os atores sociais" que os compartilham.

Sobre a relação entre a interação promovida pelo convívio social e a construção de crenças ou representações acerca do mundo social ou da realidade vivida, Georg Simmel (2006) concebeu uma teoria que sustenta a existência autônoma das interpretações sobre o mundo real ou realidade, paralelamente à realidade da qual elas se originam. 
Simmel fala sobre um "impulso para a sociabilidade", que levaria os indivíduos a se associarem aos outros movidos por interesses individuais. Para esse autor, a sociabilidade seria a forma lúdica de "sociação", de interação entre os indivíduos, "algo cuja concretude determinada se comporta da mesma maneira como a obra de arte se relaciona com a realidade", ou seja, retirando dela seu material, mas existindo de forma independente:

Com base nas condições e nas necessidades práticas, nossa inteligência, vontade, criatividade e os movimentos afetivos, elaboramos o material que tomamos do mundo. De acordo com nossos propósitos, damos a esses materiais determinadas formas, e apenas com tais formas esse material é usado como elemento de nossas vidas. Mas essas forças e interesses se liberam, de um modo peculiar, do serviço a vida que os havia gerado e aos quais estavam originalmente presos. Tornam-se autônomos, no sentido de que não se podem mais separar do objeto que formaram exclusivamente para seu próprio funcionamento e realização. (Simmel, 2006, p. 61).

Assim, Simmel exemplifica sua análise referindo-se ao conhecimento científico, que teria finalidades práticas na luta pela existência, mas adquiriria um valor em si mesmo, independentemente da sua aplicabilidade prática. $\mathrm{O}$ mesmo se daria com a arte, que decorreria da vivência no mundo, mas passaria a habitar um universo separado da vida, com valor em si mesma, retirando daquela somente aquilo que lhe interessa. Um outro exemplo, trazido pelo autor, diz respeito à interpretação da realidade.

A interpretação das realidades, concretas ou abstratas, segundo unidades espaciais, rítmicas ou sonoras, de acordo com seu significado ou organização, que seguramente surgiu das exigências de nossa prática. Contudo, essas interpretações tornam-se fins em si mesmas e exercem seu efeito por sua própria força e sua própria lei, seletivas e criativas, independentemente de seu emaranhado com a vida prática, e não por causa dela. (Simmel, 2006, p. 62).

$\mathrm{Na}$ sua teoria, conhecida como o interacionismo simbólico, Simmel (2006) consegue descrever o processo pelo qual os indivíduos na sua interação com os demais retiram da realidade seu "conteúdo", e esse adquire uma existência que é independente de sua origem no mundo social, uma existência com valor em si mesma. Esse conteúdo resultante das interações poderia ser 
chamado de representações, que constituem o presente objeto de análise, conforme procurei demonstrar, por configurarem uma existência independente e autônoma em relação à realidade e ao próprio contexto de interação do qual resultam.

Revendo os discursos das artesãs sobre a formação dos grupos e como começaram a trabalhar juntas, quando descrevem como se deu o processo, pode-se observar o recurso a imagem de uma mistura harmônica de todas as pessoas na capital federal, Brasília, sempre presente e acreditada como motivador de um resultado positivo do trabalho.

Nas falas individuais sempre é mencionada a vinda para Brasília, seguida da nova interação que se estabeleceu na capital. A reunião das artesãs com propósito de produzir artesanato é reconstruída na memória e relatada como um processo harmônico em que as diferenças seriam suprimidas e a diversidade serviria para criar algo novo, ainda que não tão diverso das práticas anteriores, já que todos os grupos relataram fazer algo que todas as integrantes já sabiam fazer antes de se reunirem, sejam bordados ou flores artesanais. Esses processos de reconstrução da memória pela narrativa podem ser observados pela repetição e pela eleição de alguns elementos mais significativos da experiência de formação dos grupos, que é narrada a partir do ponto de vista de várias participantes.

As narrativas míticas são significativas para um grupo porque geralmente estão ligadas à origem do mundo ou das coisas assim como são conhecidas hoje. São significativas porque dizem respeito a uma forma de ver o mundo e tocam nas crenças compartilhadas pelo grupo social. Podem também ser entendidas como as "cosmologias" a que Douglas (1970) se refere, como conjunto de crenças que operam no ordenamento do mundo social.

Conforme formulação de Eunice Durham (2004, p. 231): ${ }^{4}$

Um reexame dos clássicos da antropologia culturalista, tanto em sua linhagem americana, que elaborou a noção de padrão cultural, como na variante inglesa, com Malinowski e seu conceito de instituição, revela claramente que a noção de cultura parte do estabelecimento de uma unidade fundamental entre ação e representação, unidade esta que está dada em todo comportamento social.

4 O artigo de Eunice Durham foi publicado inicialmente em 1977 e republicado, por sua relevância e atualidade, em 2004.

Horizontes Antropológicos, Porto Alegre, ano 18, n. 38, p. 133-158, jul./dez. 2012 
Reunidas em Brasília, numa região central do Brasil, as artesãs trocam experiências e pontos de bordado, e acabam por concluir que no centro do Brasil se encontram representadas as variações regionais provenientes das várias localidades, resultando numa síntese de saberes e de fazeres brasileiros. Essa narrativa está sempre presente nos discursos sobre a formação dos grupos e especialmente sobre o começo dos trabalhos, conforme foi mostrado. Tanto artesãs quanto designers afirmam que as características da cidade de Brasília se fazem presentes no seu trabalho.

Porque oriundos de diferentes regiões, os habitantes não deixam de tentar transplantar os costumes e rituais de sua origem. Esta preocupação transforma a cidade em uma espécie de síntese do país. As tradições populares de todos os recantos são revitalizadas em Brasília, sendo transformadas por um inevitável sincretismo. Tal síntese não deixa de corresponder à utopia de Juscelino Kubistchek de construir uma capital capaz de ser um forte fator de integração nacional. (Laraia, 1996, p. 5).

Nas falas das entrevistadas é recorrente a ideia de Brasília como síntese do Brasil, conforme apontado por Laraia, que está presente em muitos dos discursos sobre a vida na capital. A ideia central é de que, vindas de todas as regiões do país, as mulheres de Brasília sintetizam as características da mulher brasileira. Após ter apresentado um perfil sociocultural e um pouquinho da história das artesãs de Brasília, no tocante ao seu ingresso na atividade artesanal, busco neste momento destacar algumas das representações e dos mitos que estão presentes e conformam as práticas nesse campo.

Independentemente dos ritos e práticas implementados pelo Sebrae junto aos grupos, ele atua sobre os alicerces de uma cosmologia que já existe no local, compartilhada socialmente. Se existe algo no local que pode ser utilizado para inspirar criações de design, se existem saberes tradicionais, eles não são exatamente os pontos de bordado. Esse "recurso local" que é empregado para criar objetos artesanais é de natureza imaterial e repousa nas crenças compartilhadas socialmente sobre a cidade de Brasília e sobre as pessoas que fizeram nessa cidade a sua história. Os mitos e as representações que compõem o universo do artesanato são as balizas que ao mesmo tempo permitem um certo movimento enquanto conformam as ações do sujeitos envolvidos, por meio das negociações de significados. 
O fato de o Sebrae fazer uso dos mitos e das representações, e negociar significados no decorrer dos processos de interação com designers e com grupos de artesãs, não significa que a instituição esteja mal intencionada, mas aponta e revela as relações de poder que estão por trás do uso que é feito deles, com isso revelando-se também um padrão de relações de poder dentro da sociedade brasileira. Antes de tudo, o trabalho desenvolvido pelo Sebrae sublinha o caráter autônomo dessas representações que se prestam, pela sua própria natureza maleável, a manipulações por parte dos atores sociais. Tal negociação de significado é uma via de mão dupla, pois permite que artesãs e designers também possam colocar em jogo a sua visão de atividade artesanal e a sua forma de perceber as representações que estão presentes numa relação dialógica ou interacional, que vai se construindo ao andar. $\mathrm{O}$ foco do artigo recaiu sobre essa instituição, mas a negociação de significados está presente em qualquer parte onde haja tentativas de implementar políticas públicas, porque a negociação é sempre necessária, e parte inescapável desse processo.

Não se trata, portanto, de mais um caso de apropriação pela elite de uma expressão da cultura popular, já que verificamos que a prática artesanal é fomentada nas localidades por instituições com interesses específicos, por meio de políticas públicas de incentivo, e não expressão artística realizada com fim em si mesma, embora em alguns casos isso também possa estar presente nessa atividade.

No caso em questão, trata-se do uso das representações de Brasília, enquanto conteúdo com existência autônoma, de acordo com Simmel (1971, 2006), que incluem todas as relações de prestígio e poder que estão presentes na cidade, para a produção de objetos de moda e decoração que, além disso, respondem a apelos de engajamento social. Trata-se também do uso das representações de artesão, como profissional autônomo ou associado a um grupo, que supõe certo prestígio e possibilidade de mobilidade social, dentro daquele contexto específico.

Conforme apontado por Herzfeld (1992, p. 27), os símbolos podem servir a diferentes ideologias. No caso presente, o Sebrae desenvolve um projeto de construção de identidade brasiliense, que acaba emergindo tão claramente, visivelmente feito à mão, precisamente por se localizar dentro dessa ideologia de construção da cidade e de diversidade na composição. Assim, é transmitida uma ideia de que tudo o que é feito em Brasília comunga da plasticidade e liberdade daquilo que ainda está um pouco em construção. Liberdade de poder

Horizontes Antropológicos, Porto Alegre, ano 18, n. 38, p. 133-158, jul./dez. 2012 
vir a ser algo que ainda não está cristalizado no tempo, vivendo uma possibilidade assumida de se transformar e permitindo um maior espaço para a agência individual, para o empreendedorismo e para o pioneirismo.

Fazendo um breve paralelo com a análise de Lévi-Strauss (1986) sobre o totemismo, pode-se dizer que, para o artesanato, não é relevante se as representações sobre Brasília são boas para vender, o importante é que as representações sobre Brasília nos ajudam a conhecer melhor esse universo, e entender, nesse contexto, a lógica que explica como pensam os nativos. Ou seja, o artesanato, assim como o totemismo, também é "bom pra pensar".

\section{Referências}

BOURDIEU, P. A economia das trocas simbólicas. São Paulo: Perspectiva, 1999.

BOURDIEU, P. O poder simbólico. Rio de Janeiro: Bertrand Brasil, 2000.

BOURDIEU, P. A produção da crença: contribuição para uma economia dos bens simbólicos. São Paulo: Zouk, 2002.

DOUGLAS, M. Natural symbols: explorations in cosmology. London: Barrie \& Rockliff The Cresset Press, 1970.

DURHAM, E. R. A dinâmica cultural na sociedade moderna. In: DURHAM, E. R. A dinâmica da cultura. São Paulo: CosacNaify, 2004. p. 227-235.

GEERTZ, C. A interpretação das culturas. Rio de Janeiro: LTC, 1989.

GOFFMAN, E. Interaction ritual: essays on face-to-face behavior. New York: Pantheon Books, 1967.

GOFFMAN, E. Stigma: notes on the management of spoiled identity. New York: Touchstone, 1986.

HERZFELD, M. The social production of indifference: exploring the symbolic roots of Western bureaucracy. Chicago: University of Chicago Press, 1992.

LARAIA, R. Candangos e pioneiros. Brasília: Universidade de Brasília, 1996. (Série Antropologia, n. 203). 
LÉVI-STRAUSS, C. O totemismo hoje. Lisboa: Edições 70, 1986.

MAUSS, M. Ensaio sobre a dádiva. Lisboa: Edições 70, 2001.

RABINOW, P. Antropologia da razão. Rio de Janeiro: Relume Dumará, 2002.

SAHLINS, M. Cultura e razão prática. Rio de Janeiro: Zahar, 1976.

SAPIEZINSKAS, A. De bonecas, flores e bordados: investigações antropológicas no campo do artesanato em Brasília. Tese (Doutorado em Antropologia Social)-Instituto de Ciências Sociais, Universidade de Brasília, Brasília, 2008.

SEBRAE NACIONAL. Serviço Brasileiro de Respostas Técnicas, 2009. Disponível em: $<$ http://sbrt.ibict.br/instituicoes-integrantes/sebrae-nacional $>$. Acesso em: 20 fev. 2012.

SIMMEL, G. On individuality and social forms. Chicago: University of Chicago Press, 1971.

SIMMEL, G. Questões fundamentais da sociologia: indivíduo e sociedade. Rio de Janeiro: Zahar, 2006.

VEBLEN, T. A teoria da classe ociosa: um estudo econômico das instituições. São Paulo: Ática, 1974.

Recebido em: 27/02/2012

Aprovado em: 30/07/2012 